\title{
Evangelización e inquisición
}

\section{José Ignacio González Faus, Facultad de Teología de Cataluña. \\ Centro de Reflexión Teologica, San Salvador.}

Le intolerancia es la angustia de no tener ruzón (A. Sajarov).

Los siervos que quieren segar le cizaña antes del tiempo son equellos que piensan que los falsos apostoles y los heresiarcas deben ser eliminados por la espada y los suplicios. Pero el dueño del campo no quiere que se les destruya, sino que se les tolere, pues quiźr se enmienden y, de la cizaña que eran, se tomen trigo. Si no se enmiendan déjese a su juez el cuidado de castigarlos un día... Mientras tento, hay que tolerar a los malos mezclados con los buenos, puesto que habrír más daก̃o en suprimirlos que en soportarlos (Erasmo, $\mathrm{Pa}$ ráfrasis de san Mateo 13, 24ss).

\section{Planteamiento del tema}

Es conocida la insistencia con que, a raíz del 92, se viene hablando en la Iglesia de una "nueva evangelización". En este programa es tan importante el adjetivo como el sustantivo. El mundo necesita ser reevangelizado, pero sobre todo necesita serlo de una manera nueva. Y son muchos los que han ido delineando ya los aspectos de esa novedad: una inculturación más profunda en la geografla y en la historia; una evangelización que se haga "desde los pobres"...

Las páginas que siguen intentan dar relive a otro aspecto de esa "novedad": una evangelización que se haga desde lo liberiad, tanto al exterior como al interior de la comunidad de fe. $O$, para decirlo de una manera provocativa: una evangelización "sin inquisidores" y hecha desde una Iglesia sin inquisiciones.

Semejante propuesta no se hace desde el ensueño infantil de que la libertad produce siempre el bien (personalmente tiendo mucho más a creer lo contrario), sino desde la convicción creyente de que el bien y la fe sólo son agradables a 
Dios, y sólo son simplemente tales, cuando proceden de la libertad.

En cualquier caso, nadie puede negar que la inquisición constituye una de las lacras mayores de la historia de la Iglesia y uno de los argumentos más esgrimidos para negar su carácter divino. Pretender justificarla por sus éxitos (en caso de que hayan sido realmente tales) ${ }^{1}$ sería reducir el evangelio a ese pragmatismo tan "de este mundo" para el que el fin (o aún mejor, el resultado) justifica todos los medios. La misma historia de la progresiva implantación de la inquisición, que ahora no podemos hacer (pero de la que basta con evocar aquí las condenas iniciales y las resistencias de la Iglesia a ella), muestra claramente cómo se trata de una "caída progresiva" en los lazos del príncipe de este mundo. Y lo más duro de esa lacra es que no desapareció de la Iglesia por una conversión de las autoridades eclesiásticas, sino —en la mayoría de los casos- por imposición de los poderes civiles.

Semejante lacta es absolutamente contraria al Espíritu de Jesús y a la posibilidad misma de una auténtica evangelización. Y sin embargo, no vamos a tralar aque de la "institución inquisitorial" (que en sí misma puede ser suficientemente relativizada por contextos históricos etc.), sino de algo más grave: el esptritu inquisitorial que dio origen a esa institución y que puede seguir presente en la Iglesia de hoy más allá de la desaparición de determinadas atrocidades concretas como el fuego, la cortura o la cárcel.

En este sentido, se trata de una lacra muy difícilmente evitable para la Iglesia, porque su existencia suele ser fruto de una minoría que es úpica en todas las instiuciones: la que suele llamarse "personalidad autritaria", presa de una neurosis de seguridad, y que sólo consigue escapar de ella a través de la seguridad del poder, directamente ejercido o indirectamente controlado. Es posible que la Iglesia católica padezca de una particular inmunodeficiencia ante este virus universal. Pero hay que ser conscientes de que esa vulnerabilidad vuelve muy dificiles todos los proyectos de una evangelización nueva. Porque, por un lado, falsifica la misión de la Iglesia, pervirtiéndola por el camino que Jesús rechazó en sus tentaciones, y que sustituye la libertad de la fe por las seguridades del número, del "signo del cielo" o del poder. Y, por el otro lado, amenaza a la larga con degenerar en una nueva forma de fariseísmo que "cuela el mosquito" de la fórmula o del lenguaje, para tragarse los camellos de la injusticia y la falta de misericordia.

Creo por ello que se hace necesario, como primera parte de este escrito, desenmascarar o describir un poco más ese "espíritu" que he llarnado "mentalidad inquisitorial" y que es contrario al Espíritu de Jesús. Cuando en adelante hablemos de inquisidores, no nos vamos a referir necesariamente a personajes que tuvieron ese cargo, sino exactamente a gentes que tienen esa mentalidad que varnos a intentar describir. 
Como la historia puede ser "maestra de la vida" (o dicho de manera más agustiniana, también el pecado puede ser ocasión de más grande amor y servicio a Dios), quisiera hacer esa descripción de la mentalidad valiéndome de ejemplos del pasado, testificables y conocidos. Pero repito que estamos tratando de describir una psicologla: No son unas prácticas o palabras concretas lo que nos interesa, sino el espiritu que actuaba en ellas. Porque ese espíritu (aún más que aquellas conductas pasadas) es el que hoy puede seguir impidiendo la evangelización.

Y quizás hay que repetir, antes de comenzar nuestro análisis, que nada de lo que diremos implica una negación de la autoridad en la Iglesia y de un ministerio de responsabilidad hacia la verdad de la fe. Sólo puede implicar la necesidad de encontrar maneras nuevas y más evangélicas para el ejercicio de esa responsabilidad que, además, es siempre responsabilidad bipolar (como lo son wodos los valores humanos y cristianos): conservar, pero conservar vivo, es decir, evolucionando; y enseffar, pero enseffar anunciando, es decir, no imponiendo o forzando.

Hecha esta aclaración, comencemos con nuestra descripción de la mentalidad inquisitorial.

\section{Psicología del inquisidor}

Aunque la sistematización de los textos que siguen sea artificial, intentaremos presentarla de modo que se adivine ese proceso psicológico típico de toda tentación: la pendiente por la que las turbiedades más sutiles acaban levando a infidelidades palmarias. Agruparemos ese proceso en tres capítulos, que pueden tener su correspondiente titulación con frases del Nuevo Testamento.

\section{Búsqueda de si ("Omnes quaerunt quae sua sunt, non quae Jesu Christi"} cf. Fil 2, 21)

\subsection{Sentimiento de la propia necesidad}

Vamos a comenzar por un clásico en el tema inquisitorial, el Manual de los inquisidores del cardenal Nicolau Aymerich, fechado en 1376 y que, para aquella época, cataloga una lista de 96 herejias posibles, algunas totalmente desconocidas hoy.

Dos cosas llaman la atención en varias páginas de esta obra: (a) el sentimiento de absolusa necesidad que el inquisidor tiene sobre sí mismo y sobre su labor perseculoria; y (b) la convicción de que la Iglesia vive una especie de estado de excepción (permanente por lo demás), cuya urgencia libera de toda clase de escrúpulos sobre los procedimientos a emplear. escrípulos no ya respecto a los derechos humanos del presunto reo, sino incluso respecto a las normas de 
Roma, cuya fiel aplicación puede frenar demasiado los procesos y permitir la escapatoria de los perseguidos.

El segundo punto que ahora comentaremos puede funcionar como razón del anterior. Pero antes fijémonos en este primero, acerca del cual escribe Aymerich estas reveladoras palabras:

La Iglesia puede perder muchísimo con la ausencia de los inquisidores de sus regiones, y no gana nada con su presencia en Roma. Cuando el inquisidor se aleja de la región que le ha sido confiada, renacen todas las herejlas y errores que él combatra... 2 .

La salud de la Iglesia depende casi totalmente de que existan inquisidores a mano. Este modo de sentir sobre sí mismo es uno de los rasgos más profundos de la mentalidad que buscamos. El sentimiento de responsabilidad es sin duda una virtud; pero una responsabilidad exagerada y deforme se convierte en una forma sutil de egolatria. Y el consejo de Aymerich debió calar muy hondo, puesto que volvemos a encontrarlo en otra obra posterior y también clásica, el Malleus malleficarum o martillo de las brujas.

Fechada en 1450, esta obra es un año anterior al nombramiento de Torquemada como Inquisidor y dos afios posterior a la increíble Bula de Inocencio VIII Summis desiderantes. En esta Bula, el papa admitia la existencia de los demonios íncubos y súcubos, y exhorlaba a que las prácticas sexuales de estos demonios en Alemania no carecieran del debito inquisitionis officio. En semejantes creencias se refleja quizás el miedo de la segunda mitad del siglo XV, en una Europa desgarrada por la experiencia del cisma de occidente y aterrada por la amenaza de los turcos y las oleadas de peste.

De hecho, y quizás como reflejo de ese miedo, el Martillo comienza afirmando que la creencia en brujas es conforme a la fe católica (!), y no mera superstición pagana ${ }^{3}$. Pero el miedo es un pésimo consejero, y termina fomentando ese sentimiento absoluto de la propia necesidad, úpico del inquisidor. Por eso, el Martillo insiste en que "de esta ausencia de los inquisidores derivan muchas desventajas para la Iglesia y respiros para los herejes"

En estos dos textos, leídos desde hoy, llama la atención esa absoluta convicción de la propia necesidad para Dios, que revela una dolorosa falta de sentido de la gratuidad: la gracia de que Dios pueda servirse de uno se ha convertido aqul en "la suerte" que tiene Dios de que uno se preocupe de Su causa. Probablemente, aquí reside uno de los peligros del esquema de "cristiandad": que al identificar demasiado Iglesia y mundo, acaba por vincular excesivamente la fe a una delerminada configureción del mundo.

Por eso, y dando ahora un paso más, no serd de extraftar que semejante celo espuireo por la causa de Dios se convierta muchas veces en una busca vana de la propia gloria Este será el segundo rasgo de la psicologia que estamos descri- 
biendo.

\section{Afán inconsciente de la propia gloria}

Un ejemplo preclaro de este deslizamiento psicológico to ofrece la siguiente y divertida anécdota que tomo de Marcel Bataillon.

Es sabido que la edición erasmiana del Nuevo Testamento dio lugar a una agria polémica entre su autor y el fraile español Diego López de Zúfíiga. Si esta polémica se hubiese mantenido en el campo de la crítica textual y de la traducciớn habría sido muy provechosa, pues Zúniga no era ningún incompetente en estos temas y descubrío desaciertos innegables en el texto erasmiano. Pero el fraile hispánico llevaba dentro un temperamento inquisitorial y, más allá de las discusiones cientificas, se empeñ6 en acusar a Erasmo de hereje, bien fuera por quitar el llamado comma johanneum (que hoy ya no figura en ninguna edición del Nuevo Testamento), o bien porque Erasmo afirmaba que Dios, en el Nuevo Testamento, se aplica casi siempre al Padre y "sólo en dos o tres pasajes" parece decirse del Hijo. Observación hoy también comunmente aceptada, pero que daba a Zúfiliga motivo para acusar a Erasmo de arriano.

Pues bien, poco después de estallar la polémica, y estando Zúniga en Roma, se enteró de que, además de êl, el inglés Edward Lee había publicado un opúsculo semejante al suyo, en el que también acusaba a Erasmo de preferir siempre las lecturas "que favorecian al arrianismo". Pero en lugar de alegrarse por esta coincidencia, que parecía útil para la causa de la verdad, Zúfíiga se sintió dolorosamente afectado y escribió a su amigo Juan de Vergara, quien le habla dado a conocer el opúsculo de Lee:

todo ello fue muy nuevo para mí... pues hasla entonces nunca habla visto nada de aquello, ni pensaba que nadie se hubieșe adelantado a echar garrocha a ese toro tan bravo, antes que yo; porque quisiera yo mucho aquella gloria".

En mi opinión, esta anécdota no es un simple episodio, divertido quizá, pero carente de significado, sino que expresa de la manera más ingenua, y por ello menos camuflada, lo que late en el fondo de muchas denuncias y acusaciones de herejí: la confusión de la causa de Dios con la "gloria propia", que convierte a la ortodoxia en una patente de corso para descargar la propia agresividad, como muestra el expreso deseo de "echar garrocha a ese toro". Aquf, la búsqueda común de la verdad, que es tarea del género humano, se convierte en una lidia donde al otro se le ha negado la dignidad humana (como solo es un "toro", será lícito agarrocharle), y donde los valores del otro solo son reconocidos como medio para la propia gloria (para el mérito que implica el vencer a un enemigo tan diffcil).

No hace falta repetir que asi no puede ni defenderse ni propagarse la fe y 
que, con estos sentimientos, el primer valor que resulta daflado es el de la fidelidad a la opción creyente. Ahora nos interesa más seguir con nuestro proceso psicológico: pues, tal como acabo de insinuar, de todo lo anterior se pasa muy fácilmente a una anticristiana legitimación de la propia agresividad.

\subsection{Descarga de la propia agresividad}

Esa patente de corso para la propia agresividad se expresa, también paradigmáticamente, en una dolorosa carla al arobispo Carranza, escrita por fray Francisco de Pacheco, el 20 de abril de 1549:

Nunca pensé, señor ilustrísimo, que los hombres puestos en alta dignidad eran tan envidiados, ni me podía persuadir a que los hombres viniesen a lanta desvergüenza que de la pasión hiciesen celo y por lal lo osen publicar. ambas cosas veo ahora, de las cuales tomo lección para me meter en un rincón..., y tengo empacho de la profesión de Teología que he profesado, si a tanta ceguedad en algún tiempo me hubiese de traer.

Presentar y publicar la propia pasión como virtud de celo es algo que evoca las palabras de Jesús en su discurso de despedida "llega la hora en que los que los maten creerán hacer un servicio a Dios" (Jn 16, 2). La sutil vinculación que suele hacer nuestro egoismo humano entre interes y conocimiento ha convertido esta palabra tan seria de Jesús en una de las más desapercibidas de todo el evangelio, pese a que Jesús antade que, cuando se obra asf, no se ha conocido al Padre ni a El.

Y el proceso no hace más que comenzar en este punto: porque luego, una vez se produce en la psicologia del inquisidor esta liberación de la propia agresividad, convirtiéndola en "santo celo" o en "servicio a Dios", es muy frecuente el enlace de la obsesión de ortodoxia con alguna forma de racismo, nacionalismo o cualquier otro sentimiento de superioridad grupal. Si vale la comparación, los inquisidores se convierten entonces en algo así como los ultrasur o los boixos nois de la fe: por minoritarios que sean entenebrecen la imagen de la institución en que están y, a veces, hasta pueden contar con una Ĺcita aprobación de miembros de ésta. Y si ningún grupo humano merece semejantes adeplos, mucho menos los merece la Iglesia de Jesucristo.

En la Espafta del siglo XVI tenemos otro ejemplo clásico de este fenómeno en el Estatuso de la limpieza de sangre que, amparándose en razones de ortodoxia, excluía a los cristianos nuevos de determinadas dignidades eclesiásticas etiam quantumvis pii, quantumvis probi et sancti, quantumvis sint in Christo Iesu nostraeque fidei articulis recte sentientes?. Algunos escritos contrarios a este Estaruso (como el del dominico Agustín de Salucio) fueron lisa y llanamente prohibidos.

Aquí se ve cómo una fiebre exclusiva y unilateralmente ortodoxa, sin nin- 
guna atención a la vida de la fe, acaba dafiando profundamente a ésta, y convirtiéndose en la ortodoxia de los demonios que confesaban la divinidad de Jesirs en su enfrentamiento con El. O con otras palabras, la obsesión del inquisidor por la ortodoxia (el "pensamiento reclo"), puede convertirse en un manto con que encubrir una praxis no evangélicamente "recta". Algo de esto parece que se dio por ejemplo en la enemiga del inquisidor Valdés contra el arzobispo Cerranza, por cuanto las predicas de éste contra los mayorazgos y sobre la obligación de los obispos de residir en sus diocesis, aunque fueran muy conformes a Trento, dejaban al descubierto la conducta de Valdés que habia hecho varias fundaciones para sus sobrinos y que, siendo arzobispo de Sevilla, residia habiuralmente en la corte de Valladolid.

Se impone pues, la siguiente conclusión: precisamente porque en la pura ortodoxia puede tratarse de la busca de una verdad descomprometida, reducida a objeto y no interpeladora del sujeto, y precisamente porque esa forma de verdad es intrinsecamente contraria a la naturaleza de la verdad evangélica y de la verdad de fe, se crea una pendiente para que la búsqueda "celosa" de esa ortodoxia se convierta en una sutil búsqueda de uno mismo. Y muchas veces, como muestran los ejemplos citados, ni siquiera tan sutil, aunque se ampare en la "causa de Dios" o en la defensa de la "fe del pueblo". Para defenderse de la desinstalación que la fe reclama, y que puede ser vivida como una amenaza, el inquisidor se vuelve a su vez amenazante. Para tener a raya a Dios, procura ponerse agresivamente de parte de un dios a su medida. $Y$ en esa búsqueda inconsciente de uno mismo, el eros de la verdad queda sustituido por el Thanatos de la agresividad, para decirlo con jerga freudiana. Ello se revelará en la dureza de la conducta inquisitorial, como vamos a ver en el capítulo siguiente.

\section{Falta de amor ("Veritatem faclentes contra caritatem" cf. Ef 4, 15)}

\subsection{Violencia y falto de misericordia}

La expresión de odium theologicum o rabies theologica es ya muy antigua como muestra su acuntación latina. Pero la experiencia que dio lugar a esa expresión sigue siendo dolorosamente actual: no hay peor folla de amor que la que se comete en nombre de Dios. Y si toda sociedad civil ha de poner enorme cuidado en que aquellos puestos a los que está reservado el uso de alguna violencia (policlas, militares, etc.) no sean buscados precisamente por personas de indole violenta ( $\mathrm{y}$ a veces patológicamente violenta) como tantas veces ocurre, ese mismo consejo vale para la Iglesia, aunque en ella se trate hoy de una violencia solamente espiritual.

El hecho es que, una vez la pasión se reviste de celo y la agresividad se libera, el temperamento inquisitorial encuentra en la presunta defensa de la santa fe, una excelente excusa para justificar odios o violencias no tan santas. Marcel 
Bataillon cila este sorprendente programa de Guillaume Farel contra la Exomologesis erasmiana: omnibus merdis concacandum libellum"t. Esta vez, el autor de tan evangélico objetivo no es un miembro de la Iglesia católica, sino precisamente un hombre de la reforma, lo que muestra que la tentación de manipular la Verdad de Dios en beneficio de la pasión propia no es exclusiva de un lugar o de una función, aunque pueda ser fomentada por unas esiructuras determinadas.

Tenia pues razón el obispo Fenelon cuando, a propósito de la enemiga de los jansenistas contra la célebre cuestión de "los ritos" chinos, y después de constaar que semejante agresividad hará más dafio a las misiones que favor a la fe, continúa:

Mais l'esprit qui anime les principaux actewrs est un zele amer et hawain.

On ne veut que pousser, deshonorer et vaincre. L'esprit de Dieu n'est point $1 d^{\circ}$.

Otra vez la misma constatación: la amargura y la altivez (travestidas de celo como hemos dicho), llevan al temperamento inquisidor al afán de vencer $y$ humillar. Y este proceso lo vuelve inmisericorde. Por eso, contra lo que dice la máxima más elemental de toda justicia en este mundo, el inquisidor cree que la defensa de la fe le impide siempre estar de entrada "pro reo". El está siempre de entrada contra reum, y es asi como cree estar de parte de Dios. Cree amar a Dios porque odia a aquellos que le contradicen. Pero esta frase deja deliberadamente oscuro a quién se refiere el pronombre: si a Dios o al mismo inquisidor. Con lo cual él mismo se insinúa como el más probable "hereje" o falsificador de Dios.

\subsection{Justificación de todos los medios}

El inquisidor encama asf aquella psicologfa de los fariseos desenmascarada por Jesús en el pasaje del ciego de nacimiento ${ }^{10}$. Y la conclusión que se sigue de esa mentalidad es un pavoroso endurecimiento de la conciencia que la lleva a justificar todos los medios, con la excusa de que son para defender a Dios. El Martillo de las brujas ya había recomendado que "en cuestiones de fe hay que proceder sumariamente, simplemente y brevemente"11. De ahi su insistencia en que los inquisidores, en caso de apelación del reo a Roma, no se entretengan demasiado en los engorros de la corte romana, y se las arreglen para regresar cuanto antes, porque de lo contrario los herejes, cuando se proceda contra ellos "apelarán de la misma manera", alargando su proceso con daffo de la Iglesia. La precipitación de los Apóstoles por "arrancar la cizanta", no se deliene (a pesar de la palabra en contra de Jesús) ni aunque la cizafia sea humana y, por ello mismo, no pueda ser exclusivamente cizafla. El temperamento inquisidor estŕ dispuesto a "hacer bajar fuego del cielo" aunque Jesús le reproche que no sabe de qué espíritu es $(c f . \operatorname{Lc} 9,55)^{12}$. Y si no baja fuego del cielo, él lo levantará sobre la tierra. 
Pero no es eso todo. Hoy no puede leerse sin un profundo vértigo el dato de que la Inquisición no sólo haya practicado la tortura en nombre de Dios, sino que la justificara con la advertencia de rigor, de que, si en ésta se producía muerte o lesión o derramamiento de sangre "a culpa de ella sea y no de sus mercedes los reverendos inquisidores ${ }^{n 13}$. De manera parecida, el inquisidor cree justificado el uso del engafio contra la víctima. Y M. Bataillon otra vez cuenta el caso de Mateo Pascual, vicario general del arzobispado de Zaragoza, a quien la Inquisición cito "haciéndole creer que se le convocaba como consultor" para no despertar sospechas ${ }^{14}$. Un procedimiento parecido al que utilizo el papa Paulo IV para apresar al cardenal Morone.

La violencia se justifica ası́ en defensa de la fe, aún más de lo que puede (?) justificarse en defensa del Estado. A propósito del texto de Erasmo con que hemos encabezado este artículo, el inquisidor portugués don Estevan de Almeida (quien, por lo demás, había defendido a Erasmo de muchas falsas acusaciones), considera que esa doctrina erasmiana, por evangélica que sea, resulta sumamente laxa; y que si el Estado tiene derecho a defenderse, aun con la muerte de los revolucionarios,

a fortiori, si queremos triunfar de los heresiarcas y sus favorecedores, que se esfuerzan en desviar a las almas del gobiemo espiritual, sería necesario no tolerarlos nunca, aunque fuese probable la muerie corporal's.

\subsection{El Dios del miedo}

Sé bien que algunas de estas dolorosas anécdotas tienen una respuesta "apologética" que, obsesionada por la seguridad, se incapacita para la libertad de la verdad. Es la respuesta de aquellos que atribuyen todas esas aberraciones exclusivamente al "espiriu de la época", a la mentalidad de "otros tiempos" o a la falta de un progreso histórico que, en otros muchos momentos de la discusión con el mundo, se niegan a reconocerle a éste...

No quiero negar lodo lo que ahí quepa de verdad. Pero esa respuesta soporta, sin embargo, una doble objeción importante. Su primer elemento lo constiluyen todos aquellos que ya entonces combatian semejantes aberraciones desde la "utopía" del evangelio y desde la libertad de la fe. Ellos muestran que, a pesar de la época, era posible ya entonces estar en otra posición y que a eso precisamente estaba obligada la Iglesia de Jesús: a adelantarse a cada época desde su horizonte escatológico. Ahora mismo presentaremos algunos de estos testimonios.

Pero además, hay que subrayar que lo que intentamos combatir desde aqui, no son determinadas prácticas concretas, sino más bien el espiritu que daba lugar a ellas, y que puede seguir alentando cuando el progreso histórico ya ha abolido aquellas prácticas pasadas. Ese esplritu me parece ser un espíritu de miedo, en un doble sentido: (a) ejerce la autoridad desde el miedo, mostrando la 
misma poca fe que los apostoles, hacia la promesa de Jesús (cf. Mt 28, 20). Y (b) cree que solo a través del miedo puede hacerse aceptable el Dios de Jesús, con lo que pervierte radicalmente la relación de Dios con el mundo, cuyo anuncio es clave de loda evangelización.

Pues bien, ese mismo espíritu es el que sigue vivo hoy en muchos temperamentos inquisidores. $Y$, pese al cambio de los tiempos, puede seguir generando conductas que sean proporcionalmente tan escandalosas para la mejor sensibilidad moral del siglo XX, como lo eran aquellas otras para la mejor sensibilidad del siglo XVI. Algunas conductas, como las denuncias anónimas y la escucha que se les concede ${ }^{16}$, las destituciones administrativas por las buenas, - la agresividad de muchos escritos, encaman quizá -dentro de las posibilidedes de hoy - idéntico espiritu e idéntica psicologia que los ejemplos antes citados. La pregunta que debe hacerse la Iglesia ante ellas no es si le resultan pragmáticamente "más eficaces" (cosa además discutible), sino dónde está la utopla de hoy que será la evidencia de mañana, y dónde se arrastra también el pragmatismo de hoy que sera la verglienza de mantana.

Que hacerse esta pregunta es posible, lo muestran todos los testimonios a que acabo de aludir como primera objeción: aquellas sensibilidades que en cada época se dejaron configurar más por el espiritu del evangelio que por el espifitu del siglo ( $c f$. Rom 12, 2), lo que les obligó a ser críticas, y a soportar más de un dolor por esa critica. Todos ellos trataron de poner de relieve que lo único que pueden producir las agresividades del inquisidor es miedo; y que el miedo nunca sirve ni para defender la verdad ni para dar a luz la fe:

Las conversiones que vienen del miedo duran poco: se olvida uno o levanta los hombros y se acabo. Pero si uno se ha convertido por amor de Jesús cnucificado, la conversión es más fuerte y más duradera. Lo que hizo el amor no lo hara el miedo; y cuando se acerca uno a Jesús crucificado desaparece el miedo.

Estas palabras no son de ningún teólogo centroeuropeo actual, sino de san Alfonso Marla de Ligorio, el maestro de todos los moralistas de la Iglesia ${ }^{17}$. Y Ligorio, al escribirlas no hacfa más que dar oficialidad a criterios que siglos antes habla expresado ya el maltratado Erasmo:

Por la fuerza del miedo intentamos hacer creer a los hombres lo que no creen, hacerles amar lo que no aman, forzarles a comprender lo que no comprenden. La constricción no puede ir unida a la sinceridad. Y Cristo no acepta más que el don voluntario de nuestras almas ${ }^{18}$.

Del mismo modo, es interesante conocer hoy (y ahora que nos acercamos al 92 que supuso el fin de la "Espath de las tres culturas") el juicio que merecían al P. Vitoria las medidas coercitivas contra los musulmanes: 
No se si se ha hecho bien en nuestros tiempos al compeler a los sarracenos a la fe. Se les preceptuaba o la conversión o la salida de Esparia Con frecuencia se convertian repentinamente y de ahr que muchos son malos cristianos ${ }^{19}$.

Todas estas opiniones eran minoritarias y combatidas en su tiempo. Fueron sin embargo, en su derrola, las únicas evangélicas y las que hoy evangelizan. Por eso no tendría sentido enorgullecerse hoy de ellas, si se sigue actuando en nuestro mundo con un espíritu contrario al Espiritu del que ellas brotaron. Y ese espiritu contrario al Espíritu de Dios se alimenta primariamente del miedo que sentimos todos los hombres ante la alteridad del tipo que sea. La alteridad nos desmonta puesto que el hombre ("imagen de Dios destrozada") tiende a percibirse a sí mismo como una "totalidad". De ahí esa neurosis de seguridad que degenera en la obsesión por eliminar al otro, tal como escribe Ferran Manresa: "cada uno de nosotros esta siempre tentado de eliminar de su vida al 'desconocido', de convertirse en un inquisidor"20.

Termino este apartado con un ejemplo histórico, tomado del conflicto entre san Plo V y san Felipe Neri, por la dureza bienintencionada de los procedimientos empleados por el papa para moralizar Roma Lo interesante no es la anécdota, sino la lección que de ella saca la autora que la narra:

(Pío V) indudablemente actuó por los motivos más elevados; lo cual no le impidió usar unos medios que solo podian frustrar los objetivos que se proponia. Quemar herejes no extirpa la herejía, quemar libros no destruye las ideas, recluir a los judfos en el gueto no los convierte en cristianos; expulsar a las prostitutas de la ciudad no asegura la virtud de sus clientes, ejecutar a los sodomitas no anula la sodomía. La severidad de los castigos sin duda asustó a la gente. Los individuos más recalcitrantes abandonaron la ciudad y fueron a engrosar los ejércitos de bandoleros; los débiles confesaron su culpa para escapar de lo peor sin que por ello cambiasen necesariamente sus opiniones personales. Los que más sufrieron fueron los inocentes y honrados, prendidos en las redes de la sospecha que siempre esparce este tipo de regímenes. Felipe Neri fue uno de éstos, aunque en su caso nunca sufrió el castigo efectivo; sólo la anarga prueba de la inquietud ${ }^{2 t}$.

Si en el caso de Pío $V$ pudo tratarse de una buena voluntad mal enfocada y contraproducente, hay que reconocer que, en la mayoria de los casos, se trata de un profundo desarreglo en la psicología del inquisidor. Una tal ceguera para no percibir lo antievangélico y lo evangélicamente improductivo de semejantes conductas agresivas puede que solo se explique por una secreta agresividad contra si mismo que, como pasa tantas veces, es perceptible para los demás, pero no para el sujeto que la padece. Aunque el autor que ahora voy a cilar, pueda haber sido ligero en otros momentos en que toca el tema cristiano, no es ninguna ligereza la frase de Fernando Savater sobre "la fe punitiva de quien 
castiga en los herejes la animosidad que siente contra sí mismo"22. Al menos, el hecho de que pueda ser interpretada así debería dar que pensar a la belicosidad de todos los inquisidores. Aunque claro está que, si tal reacción se produjera, sería ya la seffial de su curación...

\section{Obstinación ("ciegos, guías de ciegos", cf. Mt 15, 14)}

Esta psicología alterada llevará más de una vez al inquisidor al drama supremo de entrar en contradicción no sólo consigo mismo, sino con la Iglesia y la verdad a la que dice querer salvar. De hecho, el inquisidor contradice la fe en nombre de la defensa misma de la fe, como muestran los trazos que van a seguir.

\subsection{Desobediencia}

El lenguaje popular ha sabido caplar y expresar esta contradicción, hablando de ser "más papistas que el papa" ( $y$, para gentes constituidas en autoridad, podría hablarse igualmente de la pretensión de ser "más maestros que el magisterio de la Iglesia"). Esto será lo que en más de una ocasión convierta al inquisidor en desobediente.

Ya hemos evocado cómo el Martillo de las brujas recomendaba a los inquisidores que -al margen de cuól sea la legislación romana- ellos "se las arreglen para regresar (de Roma) lo antes posible, y no malgastar su dinero cansindose entre los enojos, las miserias, los trabajos y los gastos de la curia romana"22. Quienes se sienten defensores de Dios, siempre parecen estar por encima de esos prosaismos cotidianos entre los que se mueven los demás hombres, y entre los que -como decía santa Teresa- "lambién anda el Sefior". Si de todo ello parece seguirse algún perjuicio para la justicia de la causa, bastará con pensar que mayores daflos se siguen para la Iglesia de las contemplaciones excesivas y de la lentitud de los procesos.

Y la desobediencia puede llegar todavía más lejos. En 1527, el arzobispo Alonso Manrique, predecesor de Valdés en el cargo, pero muy distinto de él, reunió en Valladolid a todos los superiores de órdenes monásticas. Sumándose a las voces de varios obispos espanoles y del mismo papa, les prohibió formalmente que atacaran a Erasmo y "que acusen de impiedad a un hombre que ha recibido de la Santa Sede los más aduladores elogios". Explica Manrique cómo esa campanta está "visiblemente inspirada por el odio más que por el celo de la fe". Y M. Bataillon comenta:

Pero los frailes no desaprovechan tan buena ocasión para entablar pleitos contra Erasmo. Ya no son ahora, contestan, aquellos dias en que era preciso tratar con respeto a ese hombre..., para impedir que se pasase con armas y bagajes al campo de la herejla. La acción de sus libros se revela tan per- 
niciosa para la Iglesia que han tenido que levantarse contra ella: después de haber obedecido al principio los edictos que protegen a Erasmo, ahora, ante la gravedad del mal han hecho pasar la ausoridad divina anies que la autoridad humana. Se ve aparecer una fómula que irritará más de una vez a los erasmistas de España; en efecto, en el momento más agudo de la crisis, tienen los poderes de su parte, y contra los poderes constituidos es contra quienes se levanta el ejército de los frailes como una fuerza revolucionaria movilizada en nombre del interés superior de la Iglesia y de Dios ${ }^{24}$.

El dilema de tener que "obedecer a Dios antes que a los hombres" es una posibilidad que puede presentarse dolorosamente en el santuario de la conciencia y que suele obligar a cargar con cruces no pequefias. Lo extrafio de la mentalidad inquisitorial es que sólo a si misma se concede esta posibilidad; y tampoco la concibe como un drama que se vive en el santuario de la conciencia al que sólo Dios tiene acceso, sino como una identificación de la propia autoridad extema con la de Dios. Sólo el temperamento inquisidor sabe con seguridad lo que conviene a Dios y a la Iglesia.

$\mathrm{Y}$ ante esa seguridad ni siquiera valdrán las clásicas distinciones teológicas entre formas más o menos auténticas de magisterio: nuestra generación ha conocido el rechazo de Vaticano II por algunos de estos temperamentos, en nombre de tradiciones o documentos eclesí́sticos de mucho menos valor. Pero tampoco esta conducta era nueva. Y Bataillon nos descubre que la misma sospecha se había producido en la España del XVI... contra el concilio de Trento: en él estuvieron gentes que eran "sospechosas de luteranismo", como el cardenal Pole, el general de los agustinos Seripando o, el más benemérito de todos, el cardenal Morones. Por eso, fray Bernardino de Fresneda escribe sobre el "Doctor Morillo, aragonés, grande hereje, que venta del concilio de Trento y tráa de allá errores luteranos" magisterio". Y sospechas de este tipo jugaron también un papel importante en el proceso contra el arzobispo Carranza.

Esta es la razón por la que el inquisidor no puede dar su brazo a torcer, ni siquiera como "obsequio" al Dios en el que dice creer. si no es posible condenar ni prohibir los Coloquios de Erasmo, el consejo de la Inquisición le propondrá en 1535 al arzobispo Manrique retirarlos de la circulación "so título de que no estan bien traducidos ni rectamente impresos". Asf "no habra ocasión de decir que está el danto en los libros ni en el auctor, sino en la traducción e impresión, ni tendrá Erasmo de qué se quejar"mi. Todos los medios son lícitos para imponer esa pseudoseguridad que el temperamento autoritario necesita y reclama $Y$ es también en la inquisición espatiola del XVI donde parece haber nacido la costumbre de calificar proposiciones que no podfan ser condenadas como hereticas, con una serie de adjetivos induclores de sospecha ("implas, malsonantes, escandalosas, piis awibus ofensivas"...). Una astucia que resulta muy 
cómoda para el af́n de seguridad, pero absolutamente nefasta para la verdad: pues la verdad humana y cristiana se halla muchas veces más cercana al error, que una cantidad de falsedades diametralmente opuestas a aquel error concreton.

\section{Prurito autoritario}

Pero la opción por la seguridad frente a la desnudez de la verdad se hace imprescindible cuando el valor primero y principal consiste en "salvaguardar el principio (o el prurito) de autoridad". Y este valor será supremo en todo ejercicio no evangélico (es decir, no servicial) de lo ausoridad, que es lo que ocurre en los temperamentos inquisidores. He cilado en otra ocasión dos frases muy significativas sobre este punto (y también de la España del XVI): ante acusados que parecian inocentes, los inquisidores pensaban que "es menor inconveniente que padezca uno, que no hacer sospechosa su autoridad y oficio". Y el arzobispo Carranza confirma este modo de pensar cuando comentaba que "si una vez prendían a un hombre, aunque no hubiese hocho por qué, le habian de levantar algo porque no pareciese que le habian prendido livianamente"so. La afimación de que hay algún valor superior a la dignidad de la persona, aunque se trate del respeto a la autoridad, siempre conduce a este tipo de aberraciones antievangelicas.

Todas estas cosas tan serias caben en esa expresión jocosa de ser "más papistas que el papa". En el fondo, lo que esta fórmula expresa es una pretensión de ser "más poderosos que Dios". Y este es el problema último de la mentalidad inquisitorial. El hombre se asigna aquello que Dios se ha reservado de manera más exclusiva: el juicio último sobre los hombres ${ }^{30}$. Pero esta suplantación del juicio de Dios, no es sino la meta de todo un proceso de suplantación de Dios, que hemos intentado esbozar en este artículo: el sentimiento absoluto de la propia necesidad y la busca de la propia gloria acababan por suplantar la absoluta libertad y la gloria de Dios; la justificación de todos los medios divinizaba los propios fines; y el valor cuasileofánico dado al miedo para llevar a Dios sustituia también al Dios revelado en Jesús.

Ya se adivinan las consecuencias que habrán de seguirse de esa suplantación de Dios: el daflo irreparable a la causa de Dios y de la Iglesia Con ellas concluiremos esta nota, recalando por fin en el tema de la evangelización.

\section{Evangelización e inquisición}

L'affaire des jésuites que vous m'ovez mandée est déplorable. Si leurs missionaires avoient eu quelque condescendance excesive powr lewrs néophytes de la Chine, il falloit prendre autant de soin de couvrir cette faute qu'on temoigne d'empressement pow lo faire éclater. II awoit fallu les redresser secretement, el éviter un si grand scandale qui va a avilir le 
christianisme dans l'Orient, a renverser les principales missions, a faire triompher les hérétiques... ${ }^{31}$.

Quisiera llamar la atención sobre la dureza de la frase subrayada: según Fenelon, las actitudes inquisitorias "envilecen" la evangelización. Y la envilecen porque, aunque la vida de fe y la propagación de la fe tienen siempre un aspecto polémico, contra lo que san Juan llama el "pecado del mundo" o el príncipe de este mundo y el pecado del hombre, esa lucha se da sólo como fruto del amor de Dios al mundo y al hombre, al que Dios no quiere condenar, sino salvar (cf. In 3, 16-17). Por eso, no cabe en ella ninguna "economía de guerra" en la que todo vale, como la que algunos grupos propugnan hoy para definir las relaciones de la Iglesia con el mundo. La Iglesia no es la enemiga del mundo, sino sólo la representante del juicio salvador de Dios para él. Y salvar por la fuerza es imposible hasta para el mismo Dios.

Tienen pues una gran razón aquellas palabras de san Columbano a uno de sus monjes, que ya en el siglo VII expresaban algo demasiado olvidado por la Iglesia posterior: si rollis pugnam tollis et coronam. Pero también si rollis libertatem tollis dignitatem (PL 80, 273). Amar al hombre es amar su libertad, porque es amar su dignidad.

Por eso, y sin necesidad de discutir la tesis de J. Delumeau aludida en nuestra nota 1 (y que yo, personalmente, me inclino a compartir), es suficiente con sefialar aquí que, aun en el caso de que la mentalidad inquisitorial acertara siempre, a la larga sería ineficaz para evangelizar: si la verdad de la fe se ha de conservar y transmitir gracias a asesinatos, torturas, mentiras, orgullos y odios, serfa para dudar de esa verdad. Pero no se ha conservado ni transmitido gracias a, sino a pesar, de todo eso. Y hoy, mirando la historia con cierta panorámica, es posible afirmar con certeza que no fueron los hombres inquisidores, sino sus victimas, quienes, a la larga propagaron la fe. Como según Pablo, no fueron los sumos sacerdotes judíos sino el Crucificado, quien salvó al judaísmo (cf. Rom 9, $1-8$ y $11,1-12$ ).

Lo anterior valdría, como acabamos de escribir, "aunque la mentalidad inquisitorial acertara siempre". Pero aún hay que añadir que ni siquiera se cumple esta concesión: por su mismo pragmalismo egoísta y por su necesidad compulsiva de seguridad, el inquisidor se equivoca muchas veces. El cortejo de víctimas inocentes resulta hoy enormemente interpelador para una mentalidad cristiana, sin que esa interpelación se acalle por la consideración de que muchas otras víctimas eran realmente culpables. Vale paradigmáticamente de la Iglesia esa ley de la historia humana que antes hemos apuntado y que, mirando atrás, encontramos cumplida más de tres veces: que las utoplas de ayer son las evidencias de hoy, y los pragmatismos de hoy son los escándalos de mañana.

Y ninguna de estas observaciones quiere ser una incitación a la crítica negativa o a la desesperanza evangelizadora. Nadie que conozca de veras lo que 
damos "de sf" los seres humanos, podrá escandalizarse de nada de lo aqui evocado. Una experiencia humana muy elemental nos confirma cuón tremendamente difícil es para el ser humano no vincular alguna de sus pertenencias (familiar, nacional, lúdica, cultural, religiosa o eclesiáslica...) con cierta dosis de agresividad. Conno suele decir E. Levinas, "el otro" siempre es una amenaza para la propia pretensión de totalidad. De ahí esa reacción que describía $F$. Manresa y que hemos evocado en nuestra nota 20.

Por todo eso, la Iglesia nunca podrá evitar que existan en su seno temperamentos inquisidores; más aún, cuando se conoce un poco la historia es posible conceder que muchos de los inquisidores aludidos en este trabajo eran, en realidad, personas honestas y, a veces, notablemente ${ }^{32}$. Fue una cierta estructura inquisitorial eclesiástica, la que les potenció y les permitió hacer el mal so capa de bien. Por eso, la Iglesia tampoco está obligada a expulsar a los temperamentos inquisidores de su seno, sino simplemente a colocarlos en su sitio. Lo cual, repito, no será posible sin unas estructuras eclesiásticas más evangélicas.

Pero hechas estas justas concesiones a ese barro del que estamos hechos y que Dios conoce mejor que nosotros mismos ( $c f$. Sal 102,14$)$ hay que aftadir que la Iglesia no puede sin más pactar con él, porque el hombre esí́ también obligado a ser "imagen de Dios" (Gen 1, 26). Y uno de los balances que brotaban del breve estudio psicológico de nuestra primera parte es el que afirma que el inquisidor, al revés de Jesús, se empeffa en "hacer alarde de su categorla de Dios", rompiendo con ello su imagen divina ( $c f$. Fil 2,6). En efecio: a la hora de la crítica y de la condena, el temperamento inquisidor absorbe la mediación de Dios con una tranquilidad estremecedora. Mientras que, a la hora de la gloria, hemos visto también cuántas veces se la atribuye a sí mismo. En este sentido el inquisidor "toma el santo nombre de Dios en vano".

Ya he avisado de que esta observación no niega en absoluto la existencia y la necesidad de un magisterio y un ministerio apostólico en la Iglesia. Sólo los obliga a no ejercerse de la manera inquisitorial que hemos intentado describir. En este contexto, y si se quiere un ejemplo bien trivial, cabe preguntar qué sentido evangélico tienen expresiones antaño tan frecuentes como la de "Santo" Oficio; o si no estaría mejor aplicarles el dicho de Jesús: "¿por qué me llamas bueno? Nadie es bueno sino sólo Dios" (Mc 10, 18). A esto es a lo que acabo de llamar "tomar el santo nombre de Dios en vano".

Que el Soplo del Espíritu, la vida de la Iglesia y lo mejor de ella misma apuntan en la dirección aquí dibujada, lo pone de relieve este sencillo detalle numérico: más allá de las necesarias discusiones históricas sobre el significado de la palabra "anatema" según épocas históricas diversas, es bien fácil constalar que el Concilio de Trento usó 129 veces esa palabra. El Vaticano I solo 18. Y el Vaticano II ninguna. Y la evolución que ahí se adivina, y que Juan XXIII promovió en unas famosas palabras del discurso inaugural del Concilio ${ }^{33}$, no 
implica un retroceso sino un impresionante progreso evangélico.

Siguiendo en la línea de ese progreso evangélico, debemos concluir diciendo, de una manera plástica, que, si de veras se busca una nueva evangelización, habra que evitar que se produzcan reacciones como la que narra Madariaga en su novela Corazón de piedra verde: la protagonista (una muchacha de la América colombina) se hace cristiana por el rechazo que le producían los sacrificios humanos de su religión y, tras casarse con un noble hispano, viaja a Espanta, donde su proceso interior se resquebraja al asistir a los otros "sacrificios humanos" de un auto de fe de la Inquisición. Si evangelizar es comunicar una vida y no meramente "imponer un sistema", entonces se vuelve obvio que solo se puede evangelizar evangélicamente y que, de la evangelización, vale paradigmáticamente, y en un sentido mucho más rico, aquella célebre frase de Luckmann: "el medio es el mensaje"

La nueva evangelización obligará, por tanto, a contar con Dios más que con la mentalidad inquisitorial que aquí hemos descrito. Obligará por ello a que la Iglesia se pregunte ante Su Sefior - siguiendo la confesión ya iniciada por el Vaticano II- por la parte de culpa que ella misma ha tenido en la descristianización del mundo: ella, y no sólo los poderes laicos de esta tierra. Pues, como muy bien formuló el cardenal Ratzinguer en El Escorial, en 1989, la verdad sufre hoy un descrédito que proviene de que se ha pretendido propagarla a partir de la autoridad y de la fuerza... Pero "sólo la humillación de Dios abre camino a la verdad ${ }^{\text {ma }}$. Para la Iglesia sería nefasto si, teniendo hoy un papa que ha sido el campeón de la libertad de conciencia, diera la sensación de que sólo deliende esa libertad allí donde ella es minoritaria o perseguida, mientras que la olvida al interior de si misma o alli donde teme perder terreno, sustituyéndola entonces por "el derecho de la verdad".

Las aplicaciones concretas de todo esto desbordan ya el marco de este arículo. Pero existen y son a veces dolorosamente perceptibles.

\section{Conclusión}

Quiero concluir por eso con dos textos de monseffor Romero, cuya gracia esta en mantener ambos a la vez., pues el primero de ellos muestra la necesidad de algunas características de esa evangelización que se quiere que sea "nueva", mientras que el segundo pone de relieve, con el ejemplo personal de su autor, cómo esa novedad no implica una nuptura con la identidad (no ya cristiana, sino simplemente) eclesiástica:

¿Qué sabio es el Señor Jesucristo al decir a los apóstoles que vayan a evangelizar con la figura de un peregrino pobre! Y la Iglesia de hoy tiene que convertirse a esa mandato de Cristo. Ya no es tiempo de los grandes atuendos, de los grandes edificios inútiles, de las grandes pompas de nuestra Iglesia (Homilía del 15 de julio de 1979). 
Se trata de un mandaso de Cristo. Y entre los rasgos de ese mandato evangelizador entra también (con más razón aún que el evitar los estilos suntuosos) el que hemos considerado en estas líneas. No cabe separar "predicar en pobreza" y "predicar en libertad". Aunque ambos mandalos planteen numerosos problemas o parezcan crear más dificultades.

Pero, junto a esas palabras, también esta otras:

Por mi parte, quiero aprovechar esta ocasión para quienes quieren enfrentarme con la Santa Sede: el arzobispo de San Salvador se gloría de estar en comunión... respeta y ama al sucesor de Pedro... Sé que no harfa un buen servicio a ustedes, querido pueblo de Dios, si los desgajara de la unidad de la Iglesia. ¡Lejos de mí! Preferiría mil veces morir, antes que ser un obispo cismático (Homillá del 26 de agosto de 1979).

La casualidad ha hecho que concluya este articulo al día siguiente de la muerte de Mons. Lefebvre. En el, paradójicamente, coincidieron el inquisidor y el cismático. Mientras que en Mons. Romero, "renovador" y "víctima", no se dio ninguna de esas dimensiones lefebvrianas. Lo cual es más cristiano puesto que, en la Eternidad de Dios, la fidelidad a Si mismo, y la novedad siempre absoluta, coinciden.

Y esta es una de las cosas que los hombres de Iglesia todavía no hemos sabido entender de Él.

\section{Notas}

1. Ya es sabido que la tesis del historiador de la Iglesia J. Delumeau es precisamente la contraria: la "cristiandad" estaba mucho menos "cristianizada" de lo que su aspecto exterior permille sospecher. Cf. entre otros: Un chemin d'histoire. Chrétienté a christianisation, Perris 1981.

2. Le manuel des inquisiseurs, Ed. y trad. de L. Sala Molins, Paris 1973, p. 152. Citudo tambitan por J. Delumeau, Un chemin d'histoire, Paris, 1981, p. 89.

3. Pare I, quest. 1. Los autores del Malleus son dos dominicos: Heinrich Kramer y Jakob Sprenger, prior de Colonia. Hay una edición inglesa de M. Surnmers (1971) y otre francesa de A. Danet (Paris 1973) que es la que citaré.

4. Le marteau des sorcieres, Introd. y trad. de A. Danet, Paris 1973, p. 669. Citado umbien por J. Delumeau, ibid. id.

5. Citado por M. Bataillon, Erasmo y Espata, I, 139.

6. Citedo por I. I. Tellechea, El arzobispo Carranza y su tiempo, p. 136. La carta no habla en general, sino que alude cleramente a Melchor Cano y a su alianza con el inquisidor Valdes contra el arzobispo Carranza, cuando poco antes Cano "hablaba mal de su persona (de Valdés) y cuán impropio era para el oficio que tenía". En este miono anto, otra carta del dominico Hernando de san Ambrosio dice que "Cano ponía el reino en fuego por satisfacer sus rencores". Véanse en la obra citada pp. 131-137. 
7. G. M. Batnillor, op. cit. II, 311-312: "aunque seen de lo más piadosos y honrados y antos, y amque sientan rectamente de Jesucristo y de las verdades de nuestra fe".

8. Op. cir. L. p. 179.

9. Certe a M. de Chanterac. Correspondance (ed. 1828), X, 582.

10. Vesue mi comenterio en Proyecto de hermano. Visión creyente del hombre, Santunder 1987, pp. 190-191.

11. Op. cir. (an n 2) 662 .

12. La otra versión textual de este pasaje evangélico arribuye a Jesús el verbo epitimao que loa evengelistas suelen reservar para la acción de Jesús contra los demonios o para cuando se tran de una falsificación de la misión mesif́nica del Maestro. Ver sobre este punto mi artículo "La autoridad de Jesús", Sal Terree, abril 1990, 247. 268.

13. Ciu en Melgares Marin, Procedimientos de la inquisición, Madrid 1886, II, 143, a proporito del proceso de Maria Cazalla.

14. Op. cir. II, 59-60.

15. Ciudo tumbien por M. Bataillon, Ibid. I, p. 304. Subrayado mío.

16. Une préctice que ha podido ser fomentada en la Iglesia por el canon 3 del IV Concilio de Letrán (quad si quis ibidem haereticos seiverif... eos episcopo studeat indicare of. G. Alburigo, Conc. Oecum. Decreta, p. 21I). Si semejante mandato puede entenderse como interino, para una situsción lfmite, y de hace siete siglos, hoy es la miame jerarquín exlesiástica la que estaría obligada a serialar su carácter antievan. gelico. Múxime cuando, en pleno siglo XX, han ocurrido en la Iglesia fenómenos como el de La Sapinizre que, en los últimos aujos, de la sensación de haber vuelto a broter.

17. Tomo la ciu de J. Delumeau, Op. cir. (en nota 1) p. 384.

18. Carta al arzobispo de Palermo. Citada en J. Comby, Para leer la historia de la lglesia. Estella 1986, II, 11.

19. F. de Vitoria, Comentario a la 2a. 2ae. I, 193.

20. Asumir, corregir, plenificar. Una propuesta teolbgica. Cuadernos ITF, Barcelona 1991, p. 8.

21. M. Trevor, Son Felipe Neri, (Santander 1986) 116-117.

22. Cf. Etica como anor propio, Macrid 1988. p. 217.

23. Cf. Op. cit. 667.

24. Eramo y Espata, I, 275.

25. Para la trágica historia de este hombre ver L. Pastor, Historia de los papas, L VI (vol. 14), 248-263 y 398-408 (documentos). Paulo IV estaba obsesivamente (y equivocadamente) convencido de la herejía del cerdenal, a quien Pastor califica como "de vide siempre irreprensible", "uno de los mejores hombres que vivlan en la $\mathrm{Cu}$ ria" y de los "mís celosos de la reforma". El papa estaba además obsesionado por ou responsabilidad para evitar que "en lo futuro no siente el demonio a uno de los aryos en la silla de Pedro". y crela también que esa responsabilidad le autorizaba para "epartarse de las normas legales". El resultado fue una larga prisión de Morone en el castillo de Santangelo, de la que solo le liberó la muerte del papa, y el sentido comtun de su sucesor Pio IV.

26. Mid. I, 104. Los subrayados son del original.

27. Boid. II, 87. 
28. Tanto el inquisidor como el evangelizedor deberfan meditar y empaparse de aquelas palabras de E. Mersch (Thèologie du Corps Mystique, Paris 1949, p. 93): "La verded y el exror no están separados por una zona intermedia que no serín ni lo uno ni lo otro, y que sería prudente no visitar. Por el contrario, se tocan y en toda línea La verdad se extiende hasta el error aunque $\longrightarrow$ por supuesto- exclusivamente hasta el error. Pararla antes, aunque fuese para apartarse más del error, serí caer en Éte, pues serfa llamar falso lo que Lodavla es verdadero. En todas partes, pero sobre todo en los parajes peligrosos, hay que guandarse de precauciones inquietas, que har(an desviarse a los sistemas para evitar que vayan flanquemdo los abismos: ya los eviurán por ellos mismos, con tal que sean verdaderos. Pues la verdad por sI misma tiene algo que no le hace ser error jamás, sin necesidad de nuestros temores y de nuestras astucias".

29. Ver J. I. Tellechea, Tiempas recios. Inquisición y heterodoxias, Salamanca 1977, 132 y 135 .

30. Véase mi comentario a este punto en Proyecto de hermano. Visión creyente del hombre, Salamanca 1987, 211-216.

31. Fenelón, carta citada en la nota 7.

32. Véase a propósito de esto lo que digo sobre el nefasto Mons. Benigni, en la reflexión sobre La Sapinière en Memoria de Jesís. Memoria del pueblo. Sentander 1984. pp. 155-197.

33. "En nuestro tiempo, la Esposa de Cristo prefiere usar la medicina de la misericordia más que la de la severidad. Piensa que hay que remediar las necesidades mostrando la validez de su doctrina sagrada más que con condenas".

34. Las ponencias de todo este curso de la universidad de verano estín pendientes de publicación en un volumen que llevará por ứulo Jesucristo hoy. 